This journal is the official publication of Bangladesh Society of Physiologists (BSP)

Web URL: www.banglajol.info/index.php/JBSP

Abstracted /indexed in Index Copernicus, Director of Open Access Journal, HINARI Index Medicus for South East Asia Region, Google Scholar, 12OR, infobse index, Open J gate, Cite factor, Scientific indexing services

pISSN-1983-1213; e-ISSN-2219-7508

\title{
Article
}

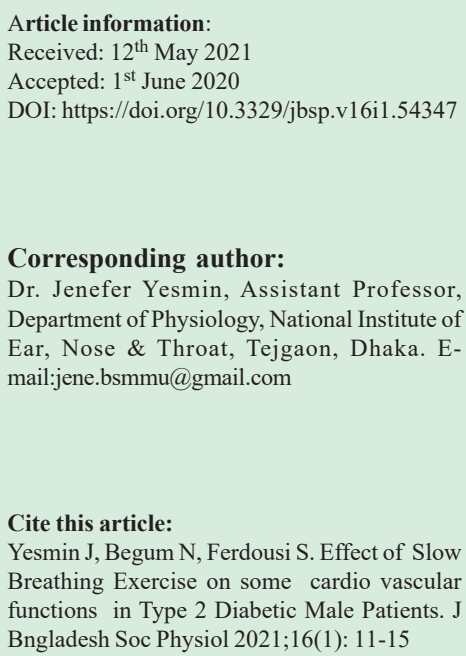

This article is open access licensed under CC BY NC SA which allows readers copy, distribute, display, and perform the work and make derivative works based on it only for noncommercial purposes.

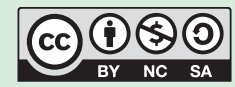

\section{Effect of Slow Breathing Exercise on some cardio vascular functions in Type 2 Diabetic Male Patients}

Jenefer Yesmin ${ }^{1}$, Noorzahan Begum ${ }^{2}$, Sultana Ferdousi ${ }^{2}$

1. Department of Physiology, National Institute of Ear, Nose \& Throat, Tejgaon, Dhaka

2. Department of Physiology, Bangabandhu Sheikh Mujib Medical University, Dhaka.

\section{Abstract}

Background: Slow breathing exercise (SBE) has some useful effects on cardiovascular system. Objectives: To observe the effects of slow breathing exercise on blood pressure in male patients with type 2 diabetes mellitus (DM). Methods: This interventional study was implemented on sixty (60) diagnosed male type 2 diabetes mellitus (T2DM) patients aged $45-55$ years with disease history 5-10 years, selected from Out Patients Department (OPD) of Endocrinology, Bangabandhu Sheikh Mujib Medical University (BSMMU), Dhaka. The subjects were divided into two groups, control group $(\mathrm{n}=30)$ included type 2 DM patients without SBE and study group included patients performing SBE for 3 months(n=30) and they were enrolled bypurposive sampling method. The study group was advised to practice SBE for 30 minutes 2 times daily for 3 months. Heart rate (HR), systolic blood pressure (SBP), diastolic blood pressure (DBP), mean arterial pressure(MAP), pulse pressure(PP) and rate pressure product (RPP)were recorded at the start of the study and after 3 months in both group of patients.. Independent sample $t$ test and paired sample t-test were used for statistical analysis and $p<0.05$ was taken as statistical significance. Results: In this study, the value of mean HR, SBP, DBP, MAP and RPP were significantly $(p<0.05)$ reduced after 3 months of SBE. Again no significant changes observed ( $p>0.05$ ) after 3 months in the group who did not practice SBE. Conclusion: Cardiovascular functions in T2DM patients was improved after performing slow breathing exercise for 3 months.

Keywords: Type 2 diabetes mellitus, blood pressure, slow breathing exercise. 
Introduction

D iabetes mellitus (DM) is a chronic disorder of hyperglycemia which occurs due to relative insulin deficiency or resistance or both. Patients with DM can lead a normal life but a long standing DM may leads to several macrovascular and microvascular complications which reduce life expectancy ${ }^{1}$. Cardiac autonomic neuropathy (CAN) is the clinically important form of complication in diabetic patients. Sudden death and silent myocardial ischemia (MI) occur in the patients with diabetes having cardiovascular autonomic neuropathy ${ }^{2}$. Hyperglycaemia causes damage to autonomic nerve fibers that innervate heart and blood vessels which is a serious complication of $\mathrm{DM}^{3}$. Resting tachycardia (>100 bpm), orthostasis (a fall of systolic blood pressure $>20$ mmHg upon standing) are some features of CAN that can affect daily activities of the type 2 diabetic patients ${ }^{4}$.

Yoga is a form ofsimple exercise which is easy to learn, inexpensive and no one need any professional personnel supervision. Pranayama or breathing exercise is one of the most popular forms of yoga based exercise. Several positive effects on cardiovascular and mental health and good compliance of breathing exercise have been seen in previous studies. It has been observed that slow breathing exercise (SBE) which is a type of pranayama that reduces sympathetic tone and mental stress ${ }^{5-6}$. SBE is a kind of stress reducing methodthat has influence on cardiorespiratory and autonomic functionsin type 2 diabetic patients ${ }^{7-8}$.

Some researchers reported that pranayama causes shifting of autonomic nervous function away from sympathetic dominance and improve cardiovascular parameters andhypertension ${ }^{9}$.

RPP is a product of multiplication of resting heart rate and systolic blood pressure. It is used as an indirect index and non-invasive method which give information of myocardial oxygen consumption that anticipate cardiac function in patients with cardiac diseases. Increased RPP is associated with increased sympathetic cardiac activity $^{10-11}$. CAN due to sympathetic predominance is observed in previous studies ${ }^{2-4}$

In this study, role of SBE on improvement of cardiovascular function in patients with T2DM has been observed by recording HR, SBP, DBP, MAP, PP and RPP.

\section{Methods}

A prospective interventional study was performed in the department of Physiology, BSMMU, Dhaka, after obtaining approval of Institutional review board. Sixty diagnosed male patients with T2DM in the age group of 45-55 years with disease duration 5-10 years were included by purposive sampling from OPD, Endocrinology, BSMMU. Oral hypoglycemic agents (OHA) and diabetic diet were the treatment protocol for this group of patients. History of chronic illness like renal and heart diseases, neurological, psychological and thyroid disorders, smoking were excluded. Sixty (60) patients were divided into two sub group, each of which consisted of 30 individuals. One group of patients performed SBE for 3 months and designated as study group. The group of patients who did not undergo SBE was considered as control. The detailed procedure of SBE and its good effects on disease were demonstrated among them who agreed to practice SBE. After recruitment, all the patients were asked to give informed written consent. All information and findings of physical examinations were written in a prefixed questionnaire. HR, SBP, DBP,MAP, PP and RPP were recorded at the start of the study and after 3 months of interval and compared.

Blood pressure was recorded by a sphygmomanometer containing aneroid manometer (ALP K2, Japan). Pulse rate was counted by placing finger over radial artery against radial bone.MAP, $\mathrm{PP}$ and rate pressure product (RPP)were manually calculated. 


\section{Breathing exercise}

The steps of SBE (alternate nostril breathing) ${ }^{12}$ were thoroughly demonstrated to the study group by organizing a training session by researcher. The baseline parameters were recorded before performing the SBE. The training of SBE was given for seven consecutive days. Then study group practiced SBE for 30 minutes twice daily for 3 months.

\section{Statistical analysis}

Pre and post interventional data for all parameters were recorded in computer Microsoft Excel. Any alterations over 3 months were analyzed by paired sample t-test. Comparison between the study and control group was analyzed by Independent sample ttest. The statistical analysis was done at 5\% level of significance and $\mathrm{p}<0.05$ was considered as statistically significance.

Results

Comparison of general characteristics and baseline HR, SBP, DBP,MAP,PP and RPP between the control and study group is given in Table I and Table II. It was observed that there was no significant $(p>0.05)$ difference in baseline values of all parameters in both group.

Table I: General characteristics in different groups $(n=60)$

\begin{tabular}{lcc}
\hline Parameters & $\begin{array}{c}\text { Control } \\
(\mathrm{n}=30)\end{array}$ & $\begin{array}{c}\text { T2 DM } \\
(\mathrm{n}=30)\end{array}$ \\
\hline Age(years $)$ & $49.9 \pm 0.49$ & $49.86 \pm 0.56$ \\
BMI $\left(\mathrm{kg} / \mathrm{m}^{2}\right)$ & $23.44 \pm 0.26$ & $23.24 \pm 0.23$ \\
FPG $(\mathrm{mmol} / \mathrm{L})$ & $7.45 \pm 0.15$ & $7.93 \pm 0.21$ \\
\hline
\end{tabular}

T2DM-Type 2 diabetes Mellitus BMI= Body mass index, $\mathrm{FPG}=$ Fasting plasma glucose. Data were expressed as Mean $\pm \mathrm{SD} \& \mathrm{P}$ value was $>0.05$.Independent sample ' $t$ ' test was done.
Table II: The values of baseline cardiovascular parameters in both groups $(n=60)$

\begin{tabular}{lcc}
\hline Parameters & Control $(\mathrm{n}=30)$ & $\mathrm{T} 2 \mathrm{DM}(\mathrm{n}=30)$ \\
\hline HR(beats/min) & $81.47 \pm 0.55$ & $82.69 \pm 0.84$ \\
$\mathrm{SBP}(\mathrm{mmHg})$ & $129 \pm 1.13$ & $129.14 \pm 1.41$ \\
$\mathrm{DBP}(\mathrm{mmHg})$ & $79.83 \pm 0.66$ & $80.34 \pm 0.89$ \\
$\mathrm{MAP}(\mathrm{mmHg})$ & $96.18 \pm 0.64$ & $97.4 \pm 0.78$ \\
$\mathrm{PP}(\mathrm{mmHg})$ & $49.17 \pm 1.18$ & $50.33 \pm 1.09$ \\
$\mathrm{RPP}(\mathrm{mmHg} / \mathrm{min})$ & $10508 \pm 113.38$ & $10852 \pm 156.02$ \\
\hline
\end{tabular}

T2DM-Type 2 diabetes Mellitus, HR= Heart rate, $\mathrm{SBP}=$ systolic blood pressure, $\mathrm{DBP}=$ diastolic blood pressure, $\mathrm{MAP}=$ mean arterial pressure, $\mathrm{PP}=$ pulse pressure, $\mathrm{RPP}=$ rate pressure product. Data were expressed as Mean $\pm \mathrm{SD} \& \mathrm{P}$ value was $>0.05$.Independent sample ' $t$ ' test was done.

Table III shows that significant reduction of HR $(\mathrm{p}<0.001)$, SBP $\mathrm{p}<0.05)$, DBP $(\mathrm{p}<0.001)$, MAP $(p<0.001)$ and RPP $(p<0.001)$ occured in type 2 diabetes mellitus patients after 3 months of SBE.

Table III: HR, SBP,DBP,MAP,PP,RPP before and after SBE in study group $(\mathrm{n}=30)$

\begin{tabular}{lcc}
\hline Parameters & Pre-SBE & Post-SBE \\
\hline HR(beats/min) & $82.69 \pm 0.84$ & $76.48 \pm 0.73^{* * *}$ \\
SBP(mmHg) & $129.14 \pm 1.41$ & $127.07 \pm 0.19^{*}$ \\
DBP(mmHg) & $80.34 \pm 0.89$ & $74.65 \pm 0.86^{* * *}$ \\
MAP(mmHg) & $97.41 \pm 0.78$ & $92.14 \pm 0.48^{* * *}$ \\
PP(mmHg) & $50.33 \pm 1.09$ & $52.50 \pm 1.47$ \\
RPP $(\mathrm{mmHg} / \mathrm{min})$ & $10852 \pm 156.02$ & $9755 \pm 128.89^{* * *}$ \\
\hline
\end{tabular}

$\mathrm{HR}=$ Heart rate, $\mathrm{SBP}=$ systolic blood pressure, $\mathrm{DBP}=$ diastolic blood pressure, $\mathrm{MAP}=$ mean arterial pressure, $\mathrm{PP}=$ pulse pressure, $\mathrm{RPP}=$ rate pressure product. Data were expressed as Mean $\pm \mathrm{SD}$. ***=p $<0.001$, $*=\mathrm{p}<0.05$.Paired sample ' $\mathrm{t}$ ' test was done.

Table IV shows that all parameters were not significantly changed ( $p>0.05)$ after 3 months in the group of diabetes mellitus who were not under SBE. 
Table IV: HR, SBP, DBP, MAP, PP, RPP at baseline and after 3 months of follow-up in control $(n=30)$

\begin{tabular}{lcc}
\hline Parameters & Baseline & After 3 months \\
\hline HR(beats/min $)$ & $81.47 \pm 0.55$ & $82.33 \pm 0.61$ \\
SBP $(\mathrm{mmHg})$ & $129.01 \pm 1.13$ & $130.17 \pm 0.97$ \\
$\mathrm{DBP}(\mathrm{mmHg})$ & $79.83 \pm 0.66$ & $79.67 \pm 0.72$ \\
$\mathrm{MAP}(\mathrm{mmHg})$ & $96.18 \pm 0.64$ & $95.69 \pm 0.63$ \\
$\mathrm{PP}(\mathrm{mmHg})$ & $49.17 \pm 1.18$ & $48.17 \pm 1.34$ \\
$\mathrm{RPP}(\mathrm{mmHg} / \mathrm{min})$ & $10508 \pm 113.38$ & $10249 \pm 345.42$ \\
\hline
\end{tabular}

$\mathrm{HR}=$ Heart rate, $\mathrm{SBP}=$ systolic blood pressure, $\mathrm{DBP}=$ diastolic blood pressure, $\mathrm{MAP}=$ mean arterial pressure, $\mathrm{PP}=$ pulse pressure, $\mathrm{RPP}=$ rate pressure product. Data were expressed as Mean \pm SD \& P value was $>0.05$.Paired sample ' $t$ ' test was done.

\section{Discussion}

The results of this study showed that there were significant reductions in HR, SBP, DBP, MAP and RPP in the study group after 3 months of yogic intervention. Similar results were reported after yogic exercise in healthy young people and hypertensive, heart failure patients ${ }^{13-18}$.

Another group of researchers also found significant decrease of HR,SBP and DBP in T2DM ${ }^{19-20}$.

It is well recognized that practicing of slow breathing exercise increases parasympathetic tone and, decreases sympathetic activity but there is no change in parasympathetic activity after practicing fast breathing exercise ${ }^{12}$.

The exact mechanism of how SBE reduces blood pressure is still under research. But research evidence has shown that performance of SBE decreases the release of adrenaline and sympathetic activity that might decrease heart rate and blood pressure. Slow breathing exercise also improves balance between sympathetic and parasympathetic nervous system ${ }^{21}$. Some other researchers also reported that yoga based exercise might increase vagal tone and decrease sympathetic activity ${ }^{13,22-23}$.
In this study, control group have shown tendency to increase blood pressure and heart rate after 3 months of follow up. Thus the results of current research emphasize the importance of performing breathing exercise along with conventional treatment in non-insulin dependent diabetic patients to maintain healthy cardiac condition.

\section{Conclusion}

Yogic slow breathing exercise may effectively improve cardiovascular function in type 2 diabetic patients. Therefore slow breathing exercise can be recommended for regular practice along with traditional medical treatment in T2DM patients to improve cardiac health.

\section{References}

1. Chimkode SM, Kumaran SD, Kanhere VV, Shivanna R. Effect of Yoga on Blood Glucose Levels in Patients with Type 2 Diabetes Mellitus. J clin Diag res 2015; 9(4):1-3.

2. Boulton AJM, Vinik AI, Arezzo JC, Bril V, Feldman EL, Freeman R, Malik RA, Maser RE, Sosenko JM, Ziegler D. Diabetic Neuropathies. Diabetes Care 2005; 28 (4): 956-962.

3. Tarvainen MP, Laitinen TP, Lipponen JA, Cornforth DJ, Jelinek HF. Cardiac autonomic dysfunction in type 2 diabetes -effect of hyperglycemia and disease duration. Front Endocrinol 2014; 5: 1-9.

4. Vinik AI, Maser RE, Mitchell BD, Freeman R. Diabetic Autonomic Neuropathy. Diabetes Care 2003; 26 (5): 1553-1579.

5. Rast SD, Hojjoti Z, Shabani R. The Effects of Yoga Training on Blood Glucose, Insulin and Resting Heart Rate in Type II Diabetic Females. J Sports Sci 2014; 2(1): $15-21$.

6. Duraiswamy V, Balasubramaniam G, Subbiah S, Veeranki SP. Role of Yoga in the Management of Type 2 Diabetes Mellitus. Int J Stud Res 2011; 1(3): 80-84.

7. Alexender GK, Innes KE, Brown CJ, Kulbok P, Bourguignon C, Bovbjerg VE, Taylor AG. Adults with or at Risk for Type 2 Diabetes Reflect on Their Experiences with Yoga Practice. Diabetes Educ 2010; 36 (6): 965-975.

8. Dhungel KU, Malhotra V, Sarkar D, Prajapati R. Effect of alternate nostril breathing exercise on

Volume 16 No. 1 June 2021: 1-15 
cardiorespiratory functions. Nepal Med Coll J 2008; 10(1): 25-27.

9. Jerath R, Edry JW, Barnes VA, Jerath V. Physiology of long pranayamic breathing: Neural respiratory elements may provide a mechanism that explains how slow deep breathing shifts the autonomic nervous system. Med Hypotheses 2006; 67(3): 566-571.

10. Verma AK, Sun J-L, Hernandez A, et al. Rate pressure Product and the components of heart rate and systolic blood pressure in hospitalized heart failure patients with preserved ejection fraction: Insights from ASCEND-HF. Clin Cardiol 2018; 41: 945-952.

11. Ferdousi S, Ferdous M, Islam MS. Impact of smoking status on autonomic functions assessed by spectral analysis of heart rate variability. Int J Clin Exp Physiol 2014; 1: 57-62.

12. Pal GK, Velkumary S, Madanmohan. Effect of ShortTerm Practice of Breathing Exercise on Autonomic Functions in Normal Human Volunteers. Indian J Med Res 2004; 120: 115-121.

13. Srivastava RD, Jain N, Singhal A. Influence of Alternate Nostril Breathing on Cardiorespiratory and Autonomic Functions in Healthy Young Adults. Indian J Physiol Pharmacol 2005; 49(4): 475-483.

14. Telles S, Yadav A, Kumar N, Sharma S, Visweswaraiah NK, Balkrishna A. Blood pressure and purdue pegboard scores in individuals with hypertension after alternate nostril breathing, breath awareness, and no intervention. Med Sci Monit 2013; 19: 61-66.

15. Anderson DE, McNeely JD, Windham BG. Regular Slow-Breathing Exercise Effects on Blood Pressure and Breathing Patterns at Rest. J Hum Hypertens 2010; 24(12) :807-813
16. Tyagi A, Cohen M. Yoga and Hypertension: a Systematic Review. Altern Ther Health Med 2014; 20(2): Review Article.

17. Krisna BH, Pal P, Pal GK, Balachander J, Jayasettiaseelon E, Sreekanth Y, Sridhar MG, Gaur GS. Effect of Yoga Therapy on Heart Rate, Blood Pressure and Cardiac Autonomic Function in Heart Failure. J Clin Diagnostic Res 2014; 8(1): 14.

18. Bhavanani AB, Sanjay Z. Immediate effect of Sukha Pranayama on Cardiovascular Variables in Patients of Hypertension. Int J Yoga Therap 2011; 21(1): 73-76.

19. Singh S, Malhotra V, Singh KP, Madhu SV, Tandon OP. Role of Yoga in Modifying Certain Cardiovascular Functions in Type 2 Diabetic Patients. JAPI 2004; 52: 203-206.

20. Shantakumari N, Sequera S, Eldeeb R. Effect of a Yoga Intervention on Hypertensive Diabetic Patients. J Adv Intern Med 2012; 1(2): 60-63

21. Upadhyay-Dhungel K, Sohal A. Physiology of nostril breathing exercises and its probable relation with nostril and cerebral dominance: A theoretical research on literature. Janaki Med Coll J Med Sci 2013; 1(1): $38-47$.

22. Jyotsna VP, Ambekar S, Singla R, Joshi A, Dhawan A, Kumar N, Deepak KK, Sreenivas V. Cardiac autonomic function in patients with diabetes improves with practice of comprehensive yogic breathing program. Indian J Endocrinol Metab 2013; 17(3): 480485.

23. Bhimani NT, Kulkarni NB, Kowale A, Salvi S. Effect of Pranayama on Stress and Cardiovascular Autonomic Function. Ind J Physiol Pharmacol 2011; 55(4): 370-377. 